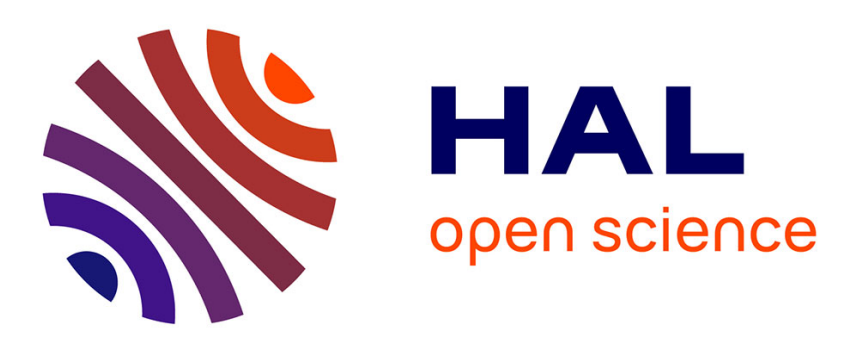

\title{
Toward proactive (eco)design process: modeling information transformations among designers activities
}

Maud Rio, Tatiana Reyes, Lionel Roucoules

\section{To cite this version:}

Maud Rio, Tatiana Reyes, Lionel Roucoules. Toward proactive (eco)design process: modeling information transformations among designers activities. Journal of Cleaner Production, 2012, 39 (January 2013), http://www.sciencedirect.com/science/article/pii/S0959652612004131. 10.1016/j.jclepro.2012.07.061,ISSN0959-6526 . hal-00763609

\section{HAL Id: hal-00763609 \\ https://hal.science/hal-00763609}

Submitted on 11 Dec 2012

HAL is a multi-disciplinary open access archive for the deposit and dissemination of scientific research documents, whether they are published or not. The documents may come from teaching and research institutions in France or abroad, or from public or private research centers.
L'archive ouverte pluridisciplinaire HAL, est destinée au dépôt et à la diffusion de documents scientifiques de niveau recherche, publiés ou non, émanant des établissements d'enseignement et de recherche français ou étrangers, des laboratoires publics ou privés. 


\title{
Toward proactive (eco)design process: modeling information transformations among designers activities
}

\author{
Maud Rio ${ }^{(1,2, *)}$, Tatiana Reyes ${ }^{(1)}$, Lionel Roucoules ${ }^{(2)}$ \\ (1) University of Technology of Troyes, 12 rue Marie Curie, 10010 Troyes, France, CNRS FRE 2848 \\ ${ }^{(2)}$ Arts et Metiers ParisTech, CNRS, LSIS, 2 cours des Arts et Metiers, 13617 Aix en Provence, France \\ ${ }^{(*)}$ Corresponding author. Tel.: +33 3515911 52. Fax: +33 3257176 98. E-mail address: maud.rio@utt.fr (M. Rio)
}

December 10, 2012

\begin{abstract}
The growing number of tools and methods for environmental impact analysis shows the variety of contexts covered by ecodesign. As ecodesign tools are evolving rapidly and manipulating different data, environmental engineers are facing some difficulties to share data efficiently with the current product designers tools. To support this data exchange among software, the capacity of tools to interoperate has been widely improved over the last ten years by software integrations. However, this paper argues that the lack of dynamism and flexibility of those solutions cannot fully face the challenge of designing ecoeffective products. Therefore, this paper proposes a three-step method to build dynamic information exchanges between environmental engineers and product designers activities involved along the design process. This proposal can be adapted to the various ecodesign contexts encountered during the design process. It also gives the capacity to the environmental engineer to use any available information produced by other designers and to give them back an adapted answer to reiterate their choices. In this paper, the proposal has been tested on an industrial case study. The results are used to discuss the benefits of developing such a method in the industry to build a constant proactivity along the design process between the environmental engineer and product designers.
\end{abstract}

\section{Introduction}

Environmental legislations oblige companies to integrate environmental concerns $\left.\left.{ }^{1}\right] 1\right]$ when designing products. Most additional environmental specifications are given to industries by the society (against global warming), customers or employees (claiming for ecolabel with different perspectives [2])[3]. The studies of Plouffe et al. [4] and the survey of Van Hemel and Cramer [3] (as an example) show that Design To Environment (DTE) approaches, that bring designers to ecodesign products, increase innovation and are indeed profitable for industries. Referring to standards [5, 6], to reduce the total environmental impacts of a product in its life cycle perspective, the environmental aspects have to be integrated during each stage of the product development. To cover this wide range of contexts, numerous and diverse ecodesign methods and tools have been developed by research centers, companies or public organisations (see for example state of the arts [7, 8]). Some authors propose to classify those supports in categories (checklists, guides, guidelines, databases, product lifecycle assessment tools, etc.) and to study their applications (see for example [9, 10]). The number of ecodesign methods and tools are

\footnotetext{
${ }^{1}$ for instance: End-of-Life Vehicles (ELV), Release of Hazardous Substances (RoHS), Registration, Evaluation, Authorisation and Restriction of Chemical substances (REACH), Waste Electrical and Electronic Equipment (WEEE), Energy-using product (EuP)
} 
still growing, as represented by a fraction of the number of publications on ecodesign methods from 1990 to 2010 , given by table 1 .

Table 1: Remarkable increase of papers dealing with "ecodesign methods": search on Science Direct

\begin{tabular}{|c|l|l|l|l|}
\hline Year & 1993 -earlier & $1994-1999$ & $2000-2005$ & $2006-2011$ \\
\hline Number of publications & 8 & 23 & 89 & 317 \\
\hline
\end{tabular}

As argued by Robert et al. [11] the ecodesign tools are complementary and must be considered in the systemic context of sustainability. However the use of the tools depends on the knowledge of the designers, their culture and the language they use [12]. Some research [13] is focusing on improving the use of the environmental tools regarding socio-cognitive issues. They point out the necessity for environmental engineers to have access to numerous data related to the product, at any moment of the design process [14]. Complementarily, researchers and industries are working on improving the capacity of environmental tools and other product designers tools to exchange informations in the systemic perspective of the Information System ([15] for instance). However, this paper argues that existing solutions provided by software industries presents some major issues to succeed in a Design To Environment approach (for instance in [15]: no appropriate support to exchange data from ecodesign tools to product designers tools, no formal data exchange in the early stage of the design process). Alternative solutions based on federation rather than on tools integration are emerging in research centers $([16,17,18]$ for instance). This paper argues that those alternative solutions present relevant properties regarding the specificity of ecodesign tools: a growing number of tools evolving rapidly and using heterogeneous data, that have to be used in the systemic perspective of sustainability. Therefore, this research proposes a method to support flexible data exchanges between tools, based on federation and specific for ecodesign contexts.

In this paper, section 2 shows three major issues faced by product designers and environmental engineers when they collaborate along the design process in a Design To Environment (DTE) perspective: the variability of ecodesign contexts, the inappropriate type of interoperability between tools and the difficulty to integrate environmental parameters among current designers parameters. Section 3 proposes a method to overcome these three difficulties based on product designers and environmental engineers tools federation. The proposal is tested in section 4 on an industrial case study. The last section concludes on the efficiency of the proposed method. Recommendations for further work are presented, that aim at evaluating the potential of proactivity brought by this method to product designers and environmental engineers during the design process.

\section{Research context: three major issues faced by product designers and environmental engineers during collaboration}

This section introduces three major issues faced by product designers and environmental engineers involved in a Design To Environment process by defining some specific aspects of the design process. Blessing and Chakrabarti [19] define Design as a complex, multi-faceted phenomenon, involving:

\footnotetext{
${ }^{2}$ Search on Science Direct by keyword: ecodesign methods
} 
- Multi-domain product designers collaboration. "Product designer" is used in the following sections as a general term for all product designers domains, whereas "environmental engineer" refers to an "ecodesign expert" (consultant specialized in ecodesign, environment, or sustainable development for instance).

- A multitude of activities and procedures and the related tools and knowledge. Adapted to this paper, the "activity" of a product designer or a environmental engineer involves their specific knowledge (mechanical, environmental knowledge) and their appropriate tools to perform their tasks (Computer Aided Design software (CAD), environmental analysis tools). The integration of the environmental aspects into the design process of products, implies to link the environmental parameters (represented with environmental impacts indicators for example) to the specific product designers parameters (mechanical properties for the mechanical designer for example), by keeping the semantic associate to the data. This is one of the difficulties of Design To Environment approach, presented in section 2.1.

- A variety of contexts. In the paper and based on [9], a Design To Environment approach deals with a wide diversity of ecodesign settings depending on the industrial contexts in which ecodesign has to be performed (this is one of the obstacles faced by designers presented in section 2.2.

- An organization. The authors, focus on the Information System of the company, which presents some technical limits regarding environmental engineers and product designers capacity to exchange information between their tools (presented in section 2.3).

\subsection{Issue 1: environmental parameters integration in the complexity of the de- sign process}

In a Design To Environment approach the complexity of designing is increased by the necessity to explore unusual domains such as biology or climatology to validate the environmental impacts of a product $([20,21])$. Karlsson and Luttropp [22] add that "EcoDesign can be interpreted as Design with more intelligent interrelationship to Nature". Natural phenomena correlated to human behavior (within the evolution of society) are hardly predictable phenomena dealing with different scales of time, which make the necessity to refer to an "ecodesign expert", during the design process of the product [23, 24]. In addition, ecodesign is characterized by the "life-cycle-thinking" which relies on a transversal integration of the environmental concern in each stage of the development of the product: from cradle to grave, or cradle to cradle [25]. Therefore, adding the environmental parameter to the usual ones (cost, quality, etc.) forces the design process to be collaborative.

In this paper collaboration means the collaborative work between multi-domain designers that take part during the design process of a product. The latin roots "com" and "laborare" of the word "collaboration" gives the etymologic signification of "labor together". Individuals who collaborate share the same goal [26]: reduce cost, increase quality and reduce environmental impact. They share the resources to reach this goal [27]. Collaboration is thus "a sine-quanon" to create value in organizations [28]. However, the environmental engineer faces some difficulties to share the environmental results with other product designers [20]. This can be due to the lack of correlation between the environmental parameters (such as the environmental impacts, etc.) and the product designers parameters (the material properties for the material engineer, the mechanical properties for the mechanical engineer, the manufacturing parameters for the manufacturing engineer, etc.). To link the environmental parameters to other domain 
parameters, some tools propose to integrate some environmental parameters in a specific software module. This is the case with some material selection tools for instance (CES Selector or Granta MI, developed by Granta Design), or some Computed Aided Software (Sustainability module in Solidworks developed by Dassault Systems). These integrations keep the semantic associated to the data. Nevertheless, these integrative solutions are not supporting multidomain designers collaboration. The first identified issue therefore concerns the fact that there is no "formal equivalences" between the environmental parameter used in this tool and the equivalent one used in a distinct environmental engineers tool. For instance, the calculation hypothesis of the "potential impact of global warming" can differ from one tool to the other.

\subsection{Issue 2: the variability of the design process in industry}

Observations made by the authors in various industries show three main types of situations where ecodesign is performed during the design process.

- Ecodesign expertise can be externalized (with a consulting agency)

- Cons: unilateral data exchanges, most of the time only a Life Cycle Assessment $\left(\mathrm{LCA}^{3}\right)$ is performed;

- Pros: the results are reliable and scientific.

- Ecodesign expertise can be treated as a distinct department in the company:

- Cons: the designers are reactive and not proactive regarding the environmental assessments and it is difficult for environmental engineers to share ecodesign knowledge with them;

- Pros: the communication and data sharing between departments are facilitated by the Information System of the company (collaborative supports).

- Ecodesign expertise can be integrated in expert activities, such as mechanical engineers activities (standard [30] as an example):

- Cons: if the ecodesign expertise is only integrated locally, it is difficult for designers to have a transversal vision required to avoid environmental impact transfers;

- Pros: the minimum of knowledge is shared between designers, environmental knowledge increases and it is possible to anticipate.

These three situations are individually related to complementary strategies, such as Design To Environment (DTE) or Design For X (DFX) approaches. As argued in previous research [31] DTE requires global, ie. transversal, considerations in order to manage the collateral impacts of the various choices taken by the different experts within the design team. This is supported by specific tools to assess the life cycle of the product (qualitative or quantitative). Whereas DFX approaches are focused on a particular improvement, such as Design For Recycling, Remanufacturing. Those approaches are most of the time integrated in a local activity, such as material selection for instance (third case presented previously). However, to tackle ecoeffective products, a DFX approach needs to be performed in pair with a DTE analysis,

\footnotetext{
${ }^{3}$ LCA, defined by the ISO standard, is a multi-criteria and systematic procedure for compiling material and energy flows of a product or service and evaluate the environmental impacts potentially generated throughout its life cycle [29].
} 
to avoid impact transfers that would potentially come from decisions taken in other product designers activities. Therefore, performing DTE, as well as DFX, requires an effective data circulation among multi-domain designers activities during the process. This can be especially difficult when the expertise is externalized (first case presented previously), which has for effect to slow down the designers capacity to quickly react during the design process in a DTE approach.

These arguments can be emphasized by referring to Karlson and Luttropp [22], when comparing ecodesign to engineering design: "the synthesizing ability in design and product development processes is dependent on dialogue and cooperation that combine visionary, creative and analytic and experience based capabilities". And they added that "EcoDesign should support and promote proactive development of such synthesizing abilities". In this paper, a proactive system is meant as a system which anticipates and is dynamic. In such a system, product designers and environmental engineers have the capacity to exchange information bilaterally at any time during the design process. This is particularly difficult, as each stage of the design process implies different activities, knowledge and tools. In other words, it implies different contexts. In the early phases of the design process for instance, "the knowledge of the product is small, but the designers freedom is large since nothing is settled yet" [32].

To summarize, a proactive design process in a DTE approach, that allows environmental decisions to be taken in the early stage of the product development process, considerably increases the chance to achieve eco-effective design [33]. This contextual adaptability of the information exchange needed to perform eco-effective design is the second major issue highlighted in this paper.

\subsection{Issue 3: interoperability in the design process}

During the design process the future product is progressively defined by the sum of Bill Of Material (BOM), which emerges from the multiple designers activities involved along the design process. This digital information constitutes the digital mock-up of the product. Improving collaboration among product designers is therefore also about improving the data exchanged through the digital mock-up, especially when $1 / 5$ of time spent by product design-

ers is about gathering information needed as input to perform a design activity [34]. So far specific collaboration has been improved by data exchange approaches, such as STandard for the Exchange of Product model data (STEP) or shared collaboration spaces as implemented in PLM (Product Life-Cycle Management) systems. PLM and PDM (Product Data Management) systems mainly rely on a central database (gathering the various files from the different experts supports) associate to a management workflow (repositories, versions, access permissions, etc.)[35].

The proposition of a workbench integrating environment tools and PLM systems conducted by Theret et al. [15] provides solutions for product designers and environmental engineers to exchange information during the design process. However, there are still two major technical limits regarding the capacity of designers with this workbench to conduct a DTE approach. Firstly, the information exchanges are unilateral: the environmental engineer can extract any available information from the digital mock-up (information coming from the designers tools), but cannot inject the results from his environmental analysis into the product designers tools. The centralized data is indeed decontextualized. This implies that the semantic associate to the data is lost. This is one reason why it is then difficult to define the transformation in the other direction: from the environmental tool to the product designers tools. Secondly, standards models (such as STEP) are used to exchange information between different software in a collaborative context. Any modification of the standard leads to the modification of each exchange 
related to each tool, which is particularly time consuming. As seen previously, ecodesign is indeed supported by various tools that should be used in a systemic perspective. The selection of the given tools depends on the context of the design process involved (type of product, type of method chosen, technology involved, etc.). Therefore, the structure of interoperability should be as flexible as possible, which is not the case with this example of integration. The third issue presented in this paper is therefore the need of a flexible interoperability between environmental expert tools and product designers tools, that is not based on standards and that keep the semantic associate to the data.

\section{Research proposal: a method to federate product designers and environmental engineers activities during the design process}

At a technical level (not linked to environmental approaches), Iraqi et al. [36] argue that interoperability supported by federative approaches are providing more flexibility than integrative approaches. The IEEE standard defines interoperability as "the ability of two systems to exchange information and use the information that has been exchanged". Interoperability can indeed be afforded by three approaches: integration, unification and federation [37]. Iraqi et al. [36] argue about federation "this distributed approach seems to be the more flexible one since only local changes have to be treated when adding new concepts". Any new model can be added by dynamical adjustment. For the author, Model Driven Engineering (MDE) is relevant to support federation. MDE relies on multiple levels of abstract representation of models (terminal models, metamodel and metametamodel). As presented by [36] "while this originates from an industrial need to have a homogeneous organization where different facets of a software system may be easily separated or combined, the proposed architecture goes beyond software or platform models and reveals itself suited for many other areas where knowledge representation, exchange and reasoning is a central preoccupation". Indeed MDE can be automated by executing transformation between two distinct models.

Now considering Design To Environment approaches, federative approaches would present some opportunities in terms of flexibility and adaptability. Nevertheless, literature does not present a clear example of a method that could federate a wide variety of environmental tools with product designers tools (not only LCA with CAD and PLM, demonstrated in the work conducted by Mathieux et al. [18]) in a systemic perspective of changing contexts, nor any types of possible data transformations between those various tools. However, as shown in other domains, federation would make synchronization possible between multi-domain tools models and the environmental tool models, even if each tool taken separately evolve rapidly. This capacity given by federation is especially suitable in a complex collaborative process, where the environmental impacts of the future product can only be calculated from the compilation of heterogeneous choices taken separately by asynchronous design activities [31]. Therefore, the authors believe that federation is appropriate to connect two data models, one from the activity of the product designer and the other from the environmental engineer activity [38]. Hence, the proposal presented in the following section is based on federation.

Based on the assumption that federation confers relevant properties regarding the three issues identified in previous section, a study has been conducted to develop a method that helps industries to overcome the previous issues.

The first stage of this study was about formulating the properties of the proposal. Then based on observations and studies (how to technically federate tools specifically in a Design To Environment process in industry), a method has been built to support the proposal. This method is addressed to all product designers and IT developers in an industrial context. The 
method is composed of three steps illustrated in this section. The three step-method has then been tested on an industrial case study, presented in section 4. The information needed to apply the three-step method have been collected by interviews.

The aim of this section is therefore to present the proposal of this research: its properties and the three-step method that can be used by designers and IT developers to deploy the proposal in industry.

\subsection{Properties of the proposal: interfaces made of knowledge transformation models}

Regarding the three major issues identified in sections 2.1, 2.2 and 2.3 the proposal confers the following properties:

- (H1.1) Be adaptable to different contexts;

- (H1.3) Involve of a minimum of specific knowledge when sharing information between product designers and environmental engineers (by least commitment);

- (H1.2) Support the circulation of any available data need;

First property: adaptation to different contexts. The environmental analysis tools are chosen according to the contextual needs (H1.1) (suitable regarding the contextual variability of ecodesign): type of design chosen, product requirements, technology involved, stage of the design process, previous projects, indicators needed, standardization, legislative requirements, etc.

Most of the time, the design process is pre-defined by the project specifications. It is therefore possible to deduce the product designers tools (software) that may be involved during the design process. Consequently, it is possible to anticipate on the type of data that may be available during the process. These outputs can be the environmental analysis tool inputs.

Considering this possible data mapping, the core of the proposal is a set of transformation models between the product designers tools outputs and the environmental analysis tools inputs. These environmental tools are available in a tool library, classified by contextual criteria. Each tool are linked to transformation models. The transformation models are defined by the related product design domain knowledge and environmental engineering knowledge involved in the transformation. The models are updated according to the evolution of the activity knowledge or tools involved in different activities.

Second property: involve of a minimum of specific knowledge when sharing information between product designers and environmental engineer. This property refers to the knowledge included in each design activity (supporting the integration of environmental parameters into product designers activities). The proposal of the interface mechanism deals with multi-domain interactions. One of the difficulties is thus to overcome the lack of understanding between the design parameters of activity $X$ and its environmental consequences. Therefore:

- The transformation model is used to transform information understood by knowledge A to the same information understood by knowledge B. Knowledge A is related to the knowledge of the designer A of the activity A, idem for B; one of these is the environmental engineer; 
- The transmitted knowledge in activity B can be represented by a plugin to help the product designer B to interpret the information (when this is appropriate). For example, some "ecodesign module" developed by CAD editors (or material selection software), can be used to display the results from the global environmental analysis to the mechanical engineering activity, in the CAD software (respectively to the material selection activity, in the material selection software). The semantic associated to the data is therefore kept during the transformation;

Third property: support the transfer of any available data needed. The available data needed to perform a given activity can be transferred to the activity which needs it (H1.2) (suitable regarding the contextual variability of ecodesign and to support the integration of environmental parameter into product designers activities). To allow this transfer, designers must define the output created by their activity, and the input they need for each tool they use. Some attributes can be added or released of the models, depending on the specificity of the process (context (1)). For example, the LCA input model will be the same as the one of a simplified LCA, except that the model will present less data to fulfill.

\subsection{A three step-method to support the proposal}

Technically, the proposal can be described as a set of transformation models defined by product designers and environmental engineers knowledge, which federate the tools involved in designers activities. The knowledge transformation models are created by following a three step method based on modeling the design process, the activities involved and the information exchanges between those activities.

\subsubsection{The modeling language supporting the proposal}

This research uses the UML (Unified Modeling Language) to model the process and the Input (I) and Output $(\mathrm{O})$ activity models, supported by the programming framework environment EMF (Eclipse Modeling Framework, groundwork based on ISO standard, Open Source). This framework is suitable to program the transformations (third step) between the UML models from the second step. Any convenient programming language can be used by developers to code the transformations. In this research the transformations are modeled by The ATLAS Transformation Language (ATL ${ }^{4}$ ). This language is composed of a transformation language, a compiler and a virtual machine, and an Integrated Development Environment (IDE) based on EMF.

\subsubsection{First step of the method: modeling the design process}

Most of the time in industry, the design processes are composed of usual activities that are sequenced differently. Therefore, the first step of this method aims to model the activities sequencing of a design process in a given context. This step is supported by UML activity diagrams. Three major points must appear on the diagram. Firstly, the product designer activities and the global and transversal environmental engineer activities should be easily identified (on Fig. 1: large rectangle). Secondly, the links between those activities should appear clearly on the diagram (arrows coming from the left side of Fig. 1). Thirdly, if the activity involves more than one tool or method, this activity should be detailed in sub-activities. So

\footnotetext{
${ }^{4}$ part of the project Eclipse M2M (Model-to-Model): http://www.eclipse.org/m2m/ developed by the team of Jean Bezivin (LINA-Nantes-France)
} 
that each sub-activity is defined by the I and $\mathrm{O}$ (on Fig. 11: small inside rectangles) needed to perform the sub-activity (on Fig. 11: small inside blue round-corner square).

Fig. 1 is an illustration of the result of the first step of this method. This diagram is an extract of the model of the sequencing of four product design activities (industrial design, supplier, mechanical engineering and technology, ergonomic) linked with an environmental engineer activity.

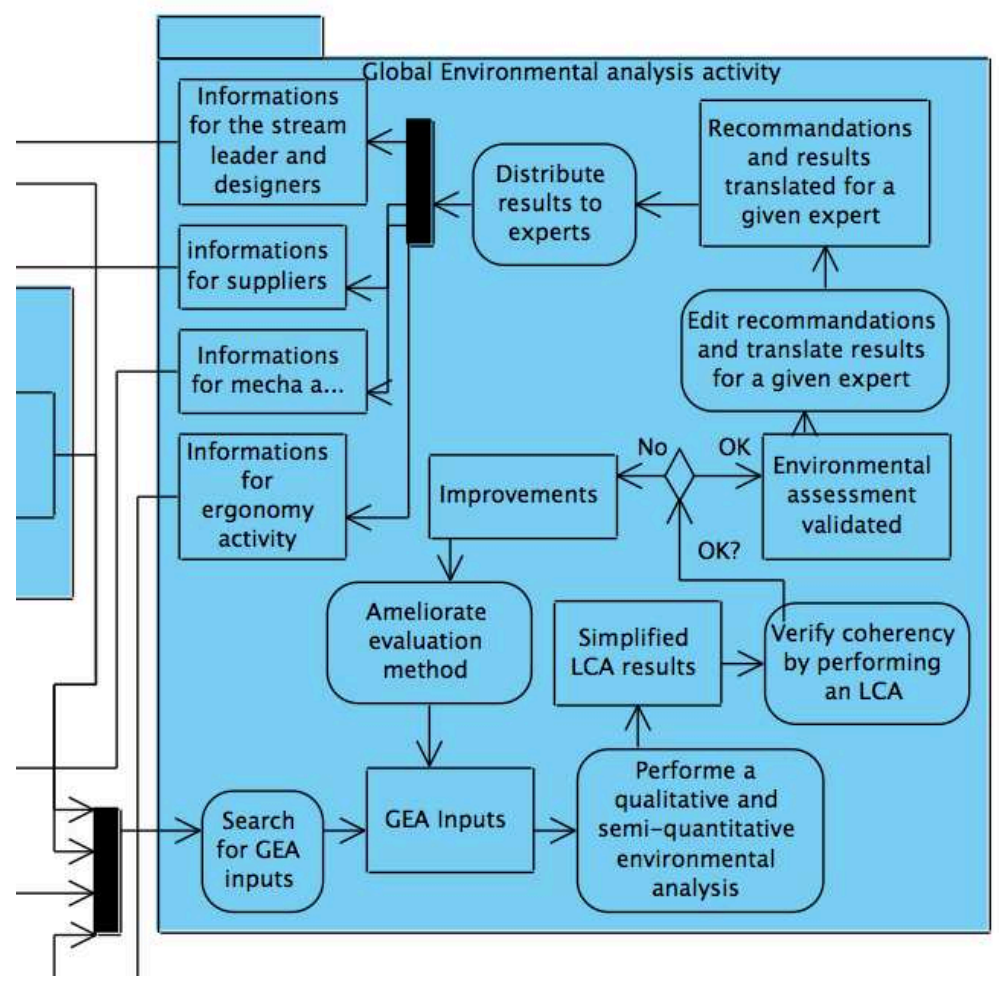

Figure 1: Extract of a design process model (including multi-domain activities involved): focus on the environmental activity

\subsubsection{Second step of the method: modeling the data involved in activities}

The second step of the method consists in modeling the data involved in each activity (or sub-activity) defined in the first step. For each sub-activity, the data needed to perform the subactivity (I) and the data created by the sub-activity (O) must be specified (I/O). This second step can be illustrated by the UML class diagram of the I needed to perform a LCA (cf. Fig 2). Classes, or elements (on Fig,2 rectangle) are linked with heritage or association (rhombus or arrows) and have some attributes, such as format, type of data. On Fig 2 the "product" for instance has for attribute its "name". This product is composed of zero-to-unlimited number of "parts" (modeled in the upper rectangle), which have their own list of attributes (listed in the rectangle). This model keeps the semantic relation between the data. Each attribute is defined by a type (string, float, character, etc. the "E" in front of each type comes from the framework used). 


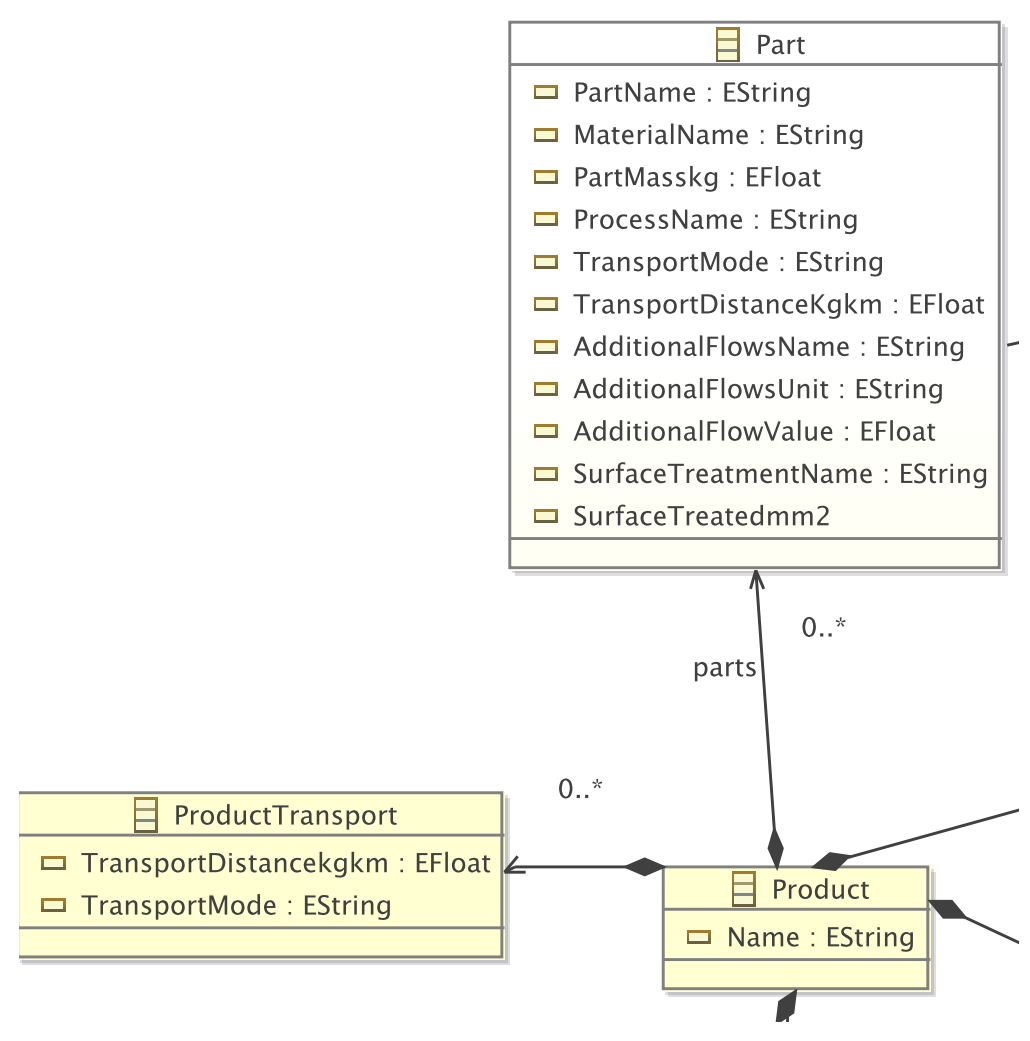

Figure 2: Extract of the UML model to describe the environmental analysis inputs needed to perform an LCA 


\subsubsection{Third step of the method: modeling the knowledge transformations}

The third step of the method is about defining and modeling the knowledge transformations needed to link the environmental engineer (sub)-activity models and product designer (sub)activity models. This step requires:

- to identify the data circulation through the design process diagram;

- to define links between the class diagrams (ie. models) that support the data: so that any available $\mathrm{O}$ from a sub-activity "is potentially" injected in another sub-activity I;

- to define and describe the "type of transformations" needed to connect the models.

This can be reached if substantial knowledge about the activity is acquired by the person who defines the transformation (most of the time, product designers or the environmental engineer). Some categorization of knowledge transformation are given in the following section.

\subsection{Categorization of knowledge transformation models}

In the third step of the method, several types of knowledge transformations can be modeled. Technically, each knowledge transformations (in ATL for instance) requires four elements: the target model, the source model, the transformation rule and several auxiliary construction. The IT developer will therefore need a clear description of this transformation (ie. what is needed to link the target model to the source model) to establish the transformation in formal language. This description (given by product designers or environmental engineers) is called in this research the knowledge associate to the transformation. The following points give some examples of operations that can be performed through descriptive knowledge transformation. They are synthesized in table 2 .

- automatic allocation: transfer the value (type: float, string, etc.) of one model attribute source to the same attribute from a target model (Fig. 3).

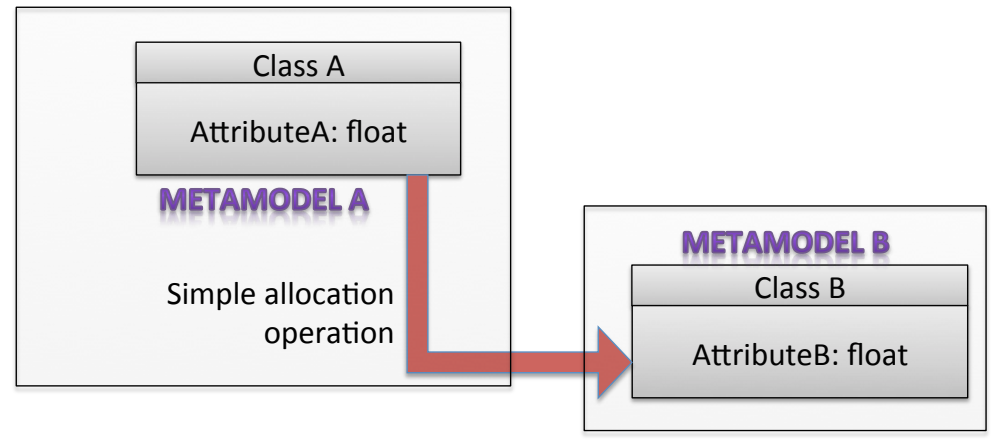

Figure 3: Illustration of an "Allocation" transformation type, between two simplified class diagrams

- database mapping: correspondence between denomination of values between a source and a target model.

Explanation: several environmental tools are based on the aggregation of energy, material flow (LCA, Mass Flow Analysis, etc.), and potential impacts. Those methods use specific databases (DDB on Fig. ), that are the result of a compilation of primary values obtained by specific organizations such as research centers. The activities related 
to material choice use other databases, sometimes from the same domain, material or manufacturing process for instance. The denomination of a given material is therefore related to a set of primary energy and material flows in databases used in LCA software (see Ecoinvent databases for instance), whereas the same material is related to a set of properties (density, Young modulus, etc.) and flows in the materials selection software. Therefore a rule based on database mapping, or database synchronization can be used to link the first activity O (on Fig. 4 Class "A", related to database "A": the material chosen by the product designer expert in material selection for instance) to the other activity Input (on Fig. 4Class "B", related to database "B": the compilation of life cycle inventories by the environmental engineer to perform a LCA, for instance).

A material designer expert edits this rule once. He allocates one (or more) material name from base A to one (or more) material name from base B (Fig. 4). Then the transformation will run automatically. Since a transformation implemented by ATL is reusable and incremental, the transformation can be updated whenever one of the databases is updated.

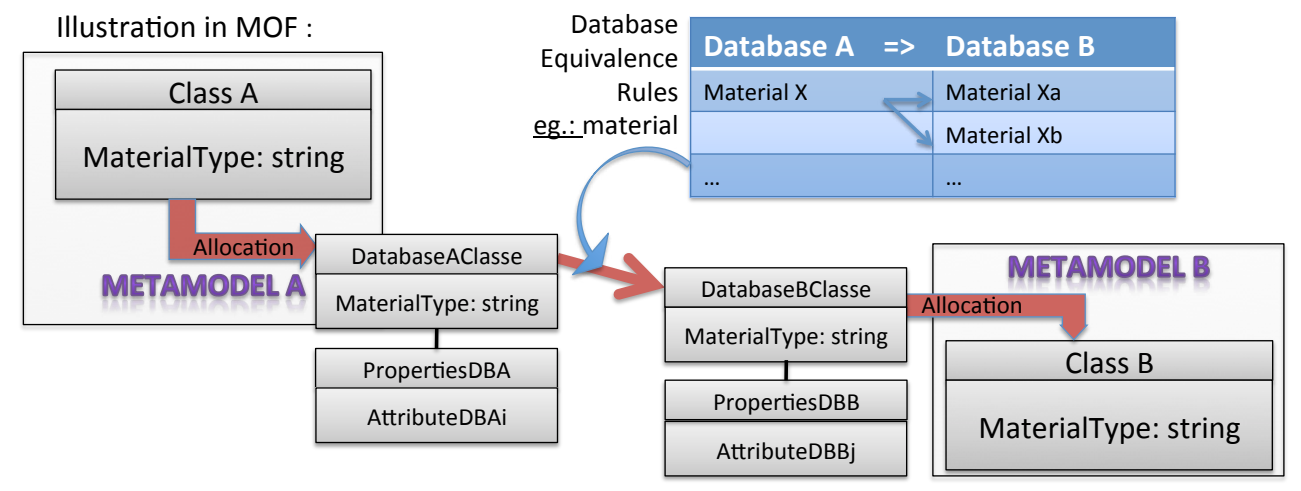

Figure 4: Illustration of a "database" transformation type, between two simplified class diagrams

- operation from one (or more) source model(s), to calculate the value needed as I in a target model (Fig. 5).

Operations can be based on operators, such as multiplications, functions (internal method related to an object type), or more complex functions (using one or more source models and one or more target models, $c f$. equation 1 of the case study for an example).

Illustration in MOF :

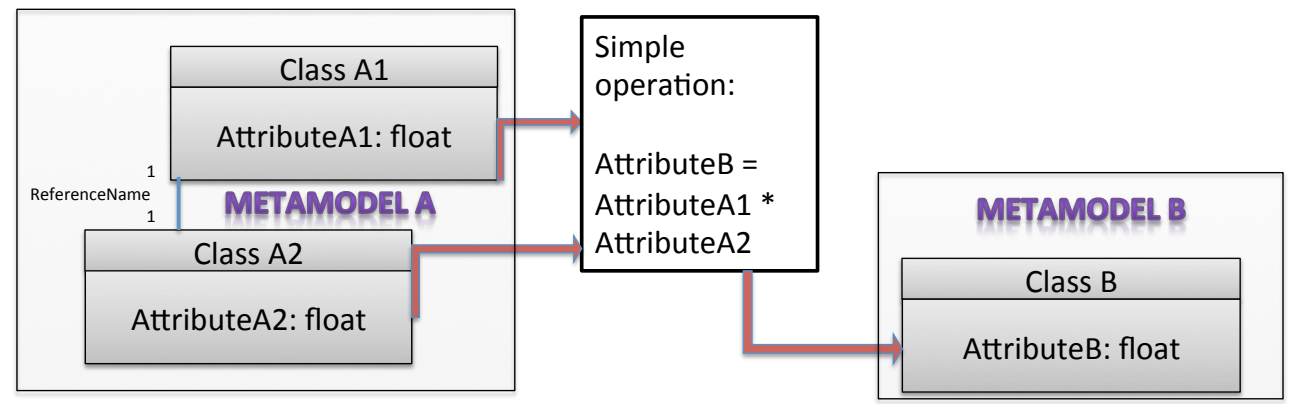

Figure 5: Illustration of an "operation" transformation type, between three simplified class diagrams 
Table 2: Categorization of knowledge transformation models

\begin{tabular}{|l|l|l|l|l|l|}
\hline & Type & General purpose & Source model & Target model & MOF \\
\hline A & Allocation & Injection of equivalent value & Value & Same value & fig 3 \\
\hline B & $\begin{array}{l}\text { Database } \\
\text { equivalence }\end{array}$ & $\begin{array}{l}\text {-Transform source denomination } \\
\text { into target denomination } \\
\text {-allocate (aggregation/distribution) }\end{array}$ & $\begin{array}{l}\text { Database } \\
\text { denomination }\end{array}$ & $\begin{array}{l}\text { Databases } \\
\text { Equivalente } \\
\text { denomination }\end{array}$ & fig 4 \\
\hline C & Operation & $\begin{array}{l}\text {-Extract several data from } \\
\text { one or more source models; } \\
\text {-perform operation; } \\
\text {-inject operation result } \\
\text { into target model. }\end{array}$ & $\begin{array}{l}\text { Several } \\
\text { values }\end{array}$ & $\begin{array}{l}\text { Operation } \\
\text { result }\end{array}$ & fig 5 \\
\hline D & Combination & Combination of A, B, C & Several values & Results & fig 6 \\
\hline
\end{tabular}


The proposal explained in this section is therefore characterized by three properties and supported by a three-step method. The following case study illustrates the application of this method industrial Design To Environment project.

\section{Case study}

\subsection{Cases study objectives}

This work has been conducted on the design process of a parking payment terminal (the New Terminal Range (NTR) project) of the Parkeon company 5 , during approximately one year (2010-2011). The objective was to test the implementation of the three-step method. At the end of the process, a comparison between the initial situation and the proposal is presented to study if the properties (presented in section 3.1) are verified with the proposal.

The early stages of a design process has been chosen to test the relevance of the knowledge transformation interfaces at the stage where the capacity to improve the environmental performance of a product is the highest.

\subsection{Activities involved: people and tools}

This case study focuses on the early stage of the NTR design process, which involves several activities listed in table 3 . In total, twelve persons have been interviewed during this study.

Table 3: Activities, related tools involved in the case study, and number of interviewed person per activity (nb.)

\begin{tabular}{|c|c|c|c|}
\hline Activity & Participant & Support (tool and method) & nb. \\
\hline Product Design & Industrial designers & CAD software: 3DS-Max® & 1 \\
\hline Product Design & Mechanical engineer & CAD software: Catia $\mathbb{R}$ & 2 \\
\hline Product Design & Ergonomics designers & CAD software: 3DS-Max $(\mathbb{R}$ & 1 \\
\hline Logistic & Logistic agents & Supply chain management system: SAP $\mathbb{R}$ & 1 \\
\hline Environment & Environmental engineers & LCA: SimaProß+ guidelines (GEDC) & 3 \\
\hline Manager & NTR project manager & Usual software such as Excel@ & 2 \\
\hline IT & Internal developer & $\begin{array}{l}\text { Enterprise Resource Planning (ERP) } \\
\text { SAPßand PLM system software }\end{array}$ & 1 \\
\hline IT & Research developer (LSIS) & EMF-UML/ATL & 1 \\
\hline
\end{tabular}

\subsection{Description of the case study process}

This case study involved the following steps. All participants ( $c f$. table 3 ) were interviewed at each step, except the IT research developer, who intervened only for the implementation and to give feedback about the limits of the knowledge transformation models.

- Application of the two first steps of the method based on observation and recorded interviews (i): observation of all activities involved (how they use their tools, how they communicate and interact with each others); general understanding of the IT system with the developer.

\footnotetext{
${ }^{5}$ The company Parkeon is a key global player in the urban mobility sector: http://www.parkeon.com/nam/, November 2011
} 
- Participants feedback from the two first steps ( $\mathbf{j}$ ): presentation of the design process diagram, class diagrams, and actual links between models; discussion and recording the critics to improve the models.

- Building with designers the knowledge transformations (third step), based on discussion (i): and validation with the IT research developer of the laboratory.

- Participants feedback from the knowledge transformations (j): general presentation and personalized propositions to each agent; recording feedbacks and improving knowledge transformation proposals.

- Technical implementation (k): of the knowledge transformations in ATL with the IT research developer from the laboratory.

- Comparison to the initial situation (l): final presentation of the proposal and comparison to initial situation; limits.

\subsection{Application of the first two steps of the three-step method}

\subsubsection{Modeling the design process}

Interviews and material study of the supports used during the NTR project have been conducted in Parkeon to describe the stages of the design process involved in this project.

- Stage 1: first requirements specification and Guidelines for Designing Ecological Concept given to the industrial designers

- Stage 2: concepts evaluation (multi-criterion)

Five aspects were evaluated through distinct activities in a specific grid gathered in a common folder: the cost/delay, the ergonomic, the logistic, the technology, the personalization and the environment. The final result was obtained by balancing the various domain evaluations. A radar graph was associated to the results so that the advantages and disadvantages were highlighted and associated to recommendations.

The activities were performed concurrently. However, various data exchanges were needed to complete the evaluations. To conduct the first simplified LCA for instance the environmental engineer needed some tangible information about the product (material, mass, process, transport), which was given by the mechanical engineers and the department of logistic, and finally reviewed by the ergonomic designer.

At the end of stage 2, a concepts ranking regarding the environmental aspects were given to the product designers and the project manager as well as environmental recommendations.

- Stage 3: evaluation of more detailed propositions

With the evaluation graph and the recommendations of the previous stage the project manager excluded four of the design propositions and specified new requirements for the four propositions left. Some design elements of a concept could be asked to be integrated to another concept.

The environmental engineer decided to adjust the environmental evaluation method used. They developed a semi-quantitative and qualitative approach based on the support they had used to communicate to the product designers: "the Guidelines for Ecological Design Concepts" (GEDC). Each guideline is balanced by specific factors. The concepts 
were evaluated through five criterion (resources, energy flows, global warming effect, toxicity and end of life).

Here again, some interactions with the mechanical engineers activity, related suppliers activity and industrial design activity were needed to conduct the evaluation.

- Stage 4: validation of the concept

After consulting all the product designers involved in the evaluation of the concept, the project manager chose the final concept.

Based on the description of these stages, the design process has been modeled in UML. Fig. 1 is an extract of this process model (activity diagram). As seen previously, on this extract is only visible the environmental analysis activity, where smaller inside square represents the I/O needed to conduct the inner sub-activities (round-corner square). In this example, the "GEA" means the "Global Environmental Analysis", which has been first a LCA, and then (because it was inappropriate to this early stage of the design process), a semi-quantitative and qualitative approach based on the support they had used to communicate to the product designers: "the Guidelines for Ecological Design Concepts" (GEDC). As seen in Fig. 1, a large part of the work conducted by the environmental engineer was about defining some personalized recommendations to the products designers involved.

\subsubsection{Modeling engineering design and environmental engineering data}

The second step of the proposed method has been done with an interview based study aiming at modeling the I/O involved in each sub-activity of the NTR design process. From Fig. 1 each I/O (small square) has been described by a UML class diagram. For example, Fig. 2 illustrates an extract of the I needed to conduct the sub-activity named "perform a Global Environmental Analysis" (simplified LCA, GEDC, etc.). On this extract, the data related to the part (name, mass, transport, additional flows), as well as the data related to the transport (distance expressed in "kgkm" (mass of the part* distance) and transport mode) are modeled.

\subsubsection{Discussion about the initial situation}

Product designers and environmental engineers have faced some difficulties in getting the data needed from others to perform their own activity. The product design folders were shared via the PLM system too late, when the design process was almost over. Interviews have shown that during the NTR process, the designers from each activity used intermediary Excel folders and organized unforeseen meetings to obtain the needed data from each other. In addition, to be aware that the needed data was available, the environmental engineer had to personally go and talk to product designers and logistic agents.

Parkeon environmental engineer has consequently developed a semi-quantitative and qualitative approach based on "Guidelines for Ecological Design Concepts" (stage 3) to reduce time consumption in compiling the life cycle inventories, and to assist designers understanding the results. Table 4 synthesizes the gaps encountered by Parkeon designers and the solutions they have developed.

The next section propose an alternative solution based on knowledge transformations, to help the environmental engineer to get the needed I from the other activities, and give back environmental results to them. 


\subsection{Third step of the proposal: proposition of knowledge transformations}

\subsubsection{Transformations from product designers to the environmental engineer}

Proposal: some interoperability solutions have been therefore suggested to NTR project Parkeon designers, to gain data exchange efficiency during the process. Referring to table 2 , the proposal is a combination of the knowledge transformation models A, B and C (figure 6).

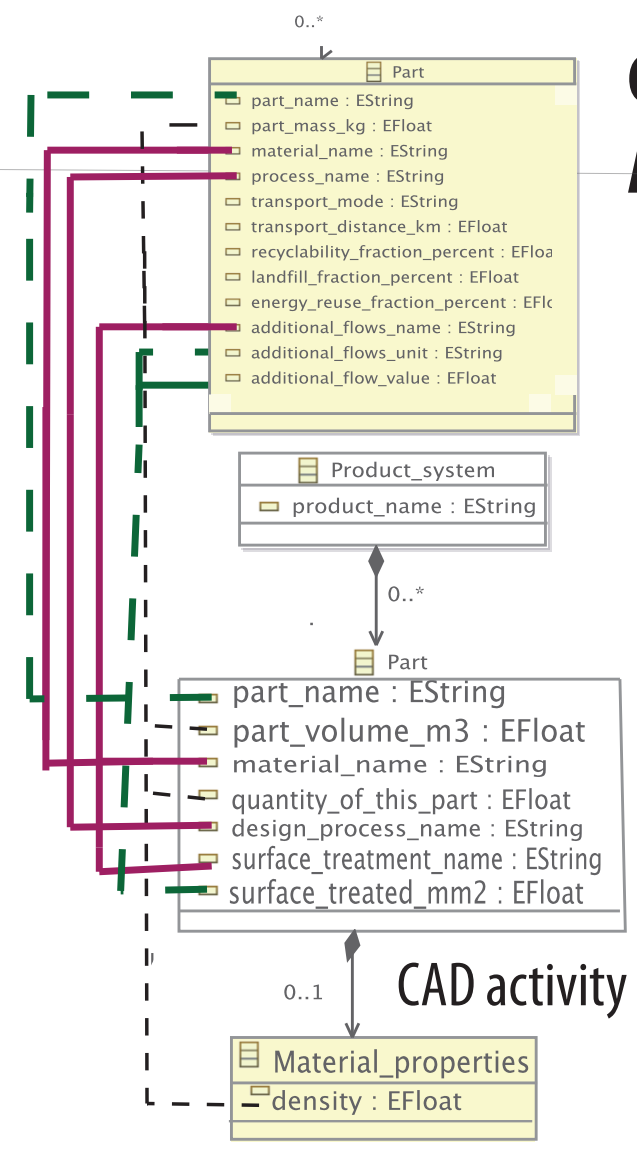

\section{Global Transforma-} Activity

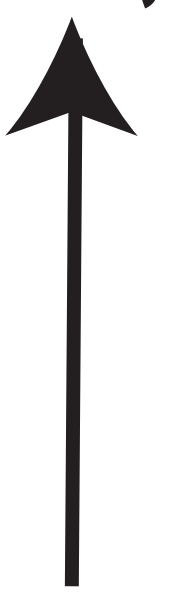
tion models (ATL) Transformations: Database equivalence

- Allocation - - - Operation

i Māsś càlculation: ${ }^{--}$,

' part_mass = part_volume * density * I

I quantity_of_this_part I

\section{Local Activity (multiple single domain)}

Figure 6: Example of knowledge transformation models between (1) structural designer activity outputs (2) logistic activity outputs and (3) environmental engineer activity inputs

Knowledge transformation type A: simple allocations were proposed to exchange data, that did not need any transformation regarding their denomination. This was the case for instance of the product and part names. Relations between product and parts are kept in this exchange, so that the product architecture was also imported from the CAD activity to the Environmental Analysis activity.

Knowledge transformation type B: Database mapping were proposed to support numerous exchanges, such as material, design process and transport mode denominations. The mechanical engineer and the environmental engineer had to define rules of equivalences between the material list related to available suppliers in the company, and the Ecoinvent (C)database of the LCA software.

Logistic agents and the environmental engineer had also to define specific mapping rules between the supply chain management system and the Ecoivent (C) database of the LCA software. 
As explained previously, those rules can be edited once by experts in those domains, to allocate one (or more) name from base A to one (or more) name from base B (Fig,4). Then the transformation runs automatically until the next update.

Knowledge transformation type $\mathbf{C}$ : operation of mass calculation

Given by equation 1 , the part mass was calculated from the multiplication of the part volume and the part material density. The volume was given by the CAD models, and the density was given by the model related to the Material database.

$$
\text { Volume }_{i}(\text { Part }) * \text { MaterialDensity }_{i}(\text { Part }) * \text { Quantity }_{i}(\text { Part })=\text { Mass }_{i}(\text { Part })
$$

As seen in this section, interoperable solutions can be found to transfer product design $\mathrm{O}$ into environmental engineering activity I. However, to transfer environmental engineering activity $\mathrm{O}$ to the local activities I, the knowledge transformations are more difficult to establish.

\subsubsection{Transformations from the environmental engineer to product designers}

Transferring all the environmental results to the other activities is technically possible with the previous transformations (table 22). However, the difficulties are about transferring the minimum needed and integrating that information into the product design activity, and then, to find an adapted representation of those results to the product designer: graphs, guidelines, etc.

As argued previously, a "life cycle based" assessment is required in a design to environment approach [39], and the standardized and scientific LCA is a relevant tool for the environment engineer. However, non environmental experts are not supposed to understand the complex LCA results. The solution argued by the authors, is to build knowledge transformation to "transfer" environmental (detailed and specific) results into appropriate results for non environmental expert product designers.

Today, some LCA software calculation methods (CML, Impact 2002+, ReCiPe, etc.) are proposing two sets of impact categories with associated sets of characterization factors: midpoint and endpoint indicators. Rules and factors to go from midpoint to endpoint indicators are the object of numerous scientific researches conducted by the LCA research community. The midpoint indicators are indeed based on impact categories. Taking the example of the ReCiPe $(2008) \sqrt{6}$ calculation method, such indicators can be: climate change, marine eutrophication, urban land occupation, etc. Most of these midpoint impact categories are further converted and aggregated into endpoint indicators. From the same example, they are based on damage categories, such as damage to human heath, damage to ecosystem diversity or damage to resource availability.

On a scientific point of view, midpoint indicators present less uncertainties, are closer from the reality. Whereas, the endpoint indicators are easier to understand for non expert, such as product designers or suppliers, but present some important uncertainties. That is why, the author proposal is to encourage the environmental engineer to perform an LCA (instead of simplified LCA), and to use interoperability to transfer results in the most appropriate set of indicators, to the product designers.

The environmental engineer has also to give a specific representation of the LCA results to emphasize the choices taken by the product designer regarding the whole impacts. Addressing the results to the material product designer for instance, the environmental engineer must find an appropriate way to show to the product designer the impacts caused by the materials chosen at each stage of the life cycle of the designed product. To support this representation, a plugin

\footnotetext{
${ }^{6}$ ReCiPe Methodology, 2008, First edition, Report I: Characterization, Goedkoop et al., 2009
} 
can be used in the software interface of the product designer. Another solution consists in using an "ecodesign module" (if available in the software) to display the environmental results. In addition, some guidelines to help the product designer reiterate his choice regarding the environmental aspects can be associated to the graphical representation.

\subsection{Synthesis of gains and obstacles given by the knowledge transformations proposal in the NTR case study}

In the two first columns, table 4 synthesizes the issues encountered by product designers and environmental engineers, and the solutions they have found to take into account the environmental analysis during the NTR project. In the lasts columns the solutions are compared to the authors proposals. The first line presents the transformations from the product designers to the environmental engineer activities and the second line presents the transformations from the latter to the former activities.

Table 4: Contribution of the knowledge interface modeling in the early stage of the NTR project

\begin{tabular}{|c|c|c|c|c|}
\hline $\begin{array}{c}\text { Transfo. } \\
\text { Types }\end{array}$ & $\begin{array}{l}\text { Issues } \\
\text { encountered }\end{array}$ & $\begin{array}{l}\text { NTR designers } \\
\text { proposal }\end{array}$ & $\begin{array}{l}\text { Authors } \\
\text { proposal }\end{array}$ & $\begin{array}{l}\text { Property } \\
\text { verified }\end{array}$ \\
\hline $\begin{array}{l}\text { from } \\
\text { Local } \\
\text { activity } \\
\text { to env. } \\
\text { act. } \\
\end{array}$ & $\begin{array}{l}\text { The ecodesigner } \\
\text { had difficulty to } \\
\text {-identify needed; } \\
\text { data; } \\
\text {-get needed data; }\end{array}$ & $\begin{array}{l}\text {-Participate to } \\
\text { unforeseen } \\
\text { meetings; } \\
\text {-Data exchanges } \\
\text { based on } \\
\text { Excel folders. }\end{array}$ & $\begin{array}{l}\text {-Identification of } \\
\text { needed data }+ \\
\text { federate supports } \\
\text { using knowledge } \\
\text { transformations } \\
\text { cf.Fig. } 6\end{array}$ & $\begin{array}{l}\text {-The proposal is ada- } \\
\text { pted to the context: } \\
\text { activities and tools; } \\
\text {-The needed data } \\
\text { is synchronized to } \\
\text { the available data; }\end{array}$ \\
\hline $\begin{array}{c}\text { from } \\
\text { env. act. } \\
\text { to Local } \\
\text { act. }\end{array}$ & $\begin{array}{l}\text { The product designers } \\
\text { had difficulty to } \\
\text {-understand results; } \\
\text {-anticipate on } \\
\text { potential impact } \\
\text { reductions. }\end{array}$ & $\begin{array}{l}\text { Develop } \\
\text { a semi- } \\
\text { quantitative } \\
\text { tool } \\
\text { based on } \\
\text { guidelines }\end{array}$ & $\begin{array}{l}\text { Keep LCA and } \\
\text { connect data via } \\
\text { rules of knowledge } \\
\text { transformations } \\
\text { to semi- } \\
\text { quantitative tool }\end{array}$ & $\begin{array}{l}\text {-The level of infor- } \\
\text { mation is adapted } \\
\text { to designers } \\
\text { knowledge }\end{array}$ \\
\hline
\end{tabular}

From local to global: the environmental engineer had difficulty compiling the Life Cycle Inventory of the product. He had to organize unforeseen meetings and ask to get data using intermediary folders. He then had to manually enter the data into the LCA tool. It was thus difficult to be aware that any information was available and time consuming to perform the LCA. He consequently decided to use a semi-quantitative tool that needed less inputs.

The author proposal was to keep performing LCA, and to develop knowledge transformations to federate product designers tools and LCA. The transformation knowledge is defined by the product designers or the environmental engineers. The proposal is thus: adapted to the activities knowledge and supports, adapted to the designers knowledge and any crucial available data can be shared.

From global to local: the environmental engineer had difficulty "translating" the environmental results to the product designers and supplier agents. He consequently developed a semiquantitative environmental evaluation linked with guidelines. Each guideline was balanced by specific factors. The concepts were evaluated through five criterion (resources, energy, global warming effect, toxicity and end of life), defined by the environmental expert and presented in a radar graph. 
The author proposal is to keep using the scientific rigor of LCA, and to use the endpoint levels of indicators to "translate" the environmental results to product designers (that are non expert in environment). The information transfer is ensured by models of transformation. Then a specific plugin can be used to represent those information into the product designer software interface. In addition, some specific guidelines are given to help the make a new choice.

\subsection{Discussion about the proposal regarding the case study}

Knowledge transformation limits: to successfully run the transformations there are some technical limits.

There must be a consensus regarding the denomination of the parts (components) of the product in the different activities (referring to the supply chain management system software for instance, as it is usually done in industries). Otherwise another solution consists in coupling a $\mathrm{C}$ transformation to a $\mathrm{B}$ one ( $c f$. Table 2).

Some information needed for the Life Cycle Inventory (LCI) cannot be formalized in the product design software related to it. This is the case for instance for manufacturing process: CAD software would have to be customized to give the possibility to the designer to inform the manufacturing process needed to build the part designed.

Databases equivalences are difficult to define when the terms have not the same level of precision. For example in material denomination, $P E$ can be a Linear low-density Polyethylene (LLDPE), a low-density Polyethylene LDPE as well as a high-density Polyethylene (HDPE). That is why the transformations must be defined by the expert of the domain they relate to.

Another difficulty can be about the data units given and used by the different supports. Units have to be expressed, transferred and converted in another unit if needed.

Knowledge transformation advantages: the approach of the proposal is unlimited in terms of additional source or target information models, as well as implementing the transformations by as much as transformation models (A, B, C, and other that can be defined) that is needed. For instance, depending on the design context of the studied project the "material engineering activity" can be dissociated from the "structural designer activity", which does not present any particular difficulty. Other example from the NTR process, it is possible for the environmental engineer to use any kind of tool that he defines to be the most appropriate: LCA, simplified LCA, matrix, etc. The models just have to be defined previously.

This shows another asset of the author proposal: more relevant tools or supports can be simply added to follow the evolution of designers knowledge. This method is therefore supporting the technological and knowledge evolution of product designers.

Finally, the definition of knowledge transformations is a way to capitalize knowledge related to the data exchanges needed between activities. The knowledge capitalization is an important issue for companies, and that is valuable. As synthesized in the right column of table 4, the proposal verifies the three properties: adaptability of different context (multi-domain activities involved, tools, knowledge, etc.), involve a minimum of specific knowledge when sharing information between activities and support the circulation of any available data needed.

\section{Discussion concerning the deployment of the proposal in indus- try}

This experimentation showed that the three-steps method was:

- adapted to industrial contexts; 
- easy to conduct if:

- product designers and environmental engineer are willing to be interviewed and to give feedback at each step;

- at least one IT developer is experimented in EMF and knows how to use UML and ATL languages (open source);

By the end, a proposal can be built to federate environmental engineering tools and product designers tools. This proposal confers the properties presented in section 3.1, which helps designers to overcome the three major issues identified in sections 2.1, 2.2 and 2.3. The proposal improves product designers and environmental engineers collaboration by giving them the capacity to exchange information dynamically and bilaterally with the other designers. Lastly, the proposal presents the advantage to formalize data in models, which keeps the semantic associate to the data, which can be particularly useful in the early stage of the design process, where the information is not settled yet.

\section{Conclusion and recommendation for further work}

In this work it was found that the collaboration between the product design and environmental engineers activities suffers from three major issues: the difficulty to integrate environmental parameters into the current parameters involved in the multi-domain activities of the design process, the variability of ecodesign contexts, and the technical limits existing in current Information Systems.

To overcome those obstacles, the paper proposal is based on three properties: the collaboration support between product designers and environmental engineer must be adaptable to different contexts; must involve a minimum of specific knowledge when sharing information and must support the circulation of any available data needed.

Therefore, the authors have proposed a three-step method to allow any future and actual environmental support to interoperate with any product design tool involved during the design process. This federation of tools helps multi-domain designers to work proactively and to assess both local and global performance. This strongly links DFX activities and DTE approaches.

As shown in the case study, the three step-method based on interviews and implemented with free and open source software, is easy to handle by product designers and IT developers, and adapted to industries.

The authors are currently working on measuring the benefits of the proposal, such as its abilities to support proactivity at each step of the Design To Environment process (in terms of environmental improvements, designers frustrations, time gains, for instance). The longterm benefits are also the object of current research, notably on the company scale: regarding financial gains and intangible gains (such as eco-effectiveness, knowledge capitalization).

\section{Acknowledgement}

The author wishes to thank the industry Parkeon (Christian Longet) that contributed to this research. Also, colleague Olivier Flambeau from LSIS laboratory is deeply acknowledged for his support for EMF developments. 


\section{References}

[1] A. Gehin, P. Zwolinski, D. Brissaud, A tool to implement sustainable end-of-life strategies in the product development phase, Journal of Cleaner Production (16) (2008) p. 566-576.

[2] C. Bratt, S. Hallstedt, K.-H. Robèrt, G. Broman, J. Oldmark, Assessment of eco-labelling criteria development from a strategic sustainability perspective, Journal of Cleaner Production (19) (2011) 1631-1638.

[3] C. van Hemel, J. Cramer, Barriers and stimuli for ecodesign in smes, Journal of Cleaner Production 10 (2002) 439-453.

[4] S. Plouffe, P. Lanoie, C. Berneman, M.-F. Vernier, Economic benefits tied to ecodesign, Journal of Cleaner Production 19 (2011) 573-579.

[5] ISO (International Organization for Standardization) Environmental ManagementIntegrating Environmental Aspects into Product Design and Development. ISO/TR14062:2002(F), ISO, Geneva, 2002.

[6] ISO (International Organization for Standardization) Environmental management systems - Guidelines for incorporating ecodesign. ISO 14006: 2011, ISO, 2011.

[7] H. Baumann, F. Boons, A. Bragd, Mapping the green product development field: engineering, policy and business perspectives, Journal of Cleaner Production 10 (5) (2002) 409-425.

[8] S. Byggeth, E. Hochschorner, Handling trade-offs in ecodesign tools for sustainable product development and procurement, Journal of Cleaner Production 14 (15-16) (2006) 1420-1430.

[9] P. Knight, J. Jenkins, Adopting and applying eco-design techniques: a practioner's perspective, Journal of Cleaner Production 17 (5) (2008) 549-558.

[10] M. D. Bovea, V. Pérez-Belis, A taxonomy of ecodesign tools for integrating environmental requirements into the product design process, Journal of Cleaner Production 20 (1) (2012) 61-71.

[11] K. H. Robèrt, B. Schmidt-Bleek, J. Aloisi de Larderel, G. Basile, J. L. Jansen, R. Kuehr, P. Price Thomas, M. Suzuki, P. Hawken, M. Wackernagel, Strategic sustainable development - selection, design and synergies of applied tools, Journal of Cleaner Production 10 (3) (2002) 197-214.

[12] L. Vicky, Ecodesign tools for designers: defining the requirements, Journal of Cleaner Production 14 (15-16) (2006) 1386-1395.

[13] F. Vallet, D. Millet, B. Eynard, How ecodesign tools are really used- requirements list for a context-related ecodesign tool, CIRP 2010.

[14] F. Vallet, M. Messaadia, B. Eynard, Sustainability requirements deployment in productprocess eco-design, IMS2020 (2010) 18.

[15] J.-P. Theret, P. Zwolinski, F. Mathieux, Integrating cad, plm and lca: a new architecture and integration proposal, International Conference on Renewable Energy and Eco-Design in Electrical Engineering (Lille) (2011) 1-6. 
[16] M. Iraqi, M. Kleiner, L. Roucoules, Tools interoperability in engineering design using model-based engineering, in: Proceedings of the 11th Biennial Conference on Engineering Systems Design and Analysis ESDA2012, France, 2012.

[17] F. Segonds, M. Iraqi-Houssaini, L. Roucoules, P. Véron, A. Aoussat, The use of early design tools in engineering processes: a comparative case studies, Int. J. of Design and Innovation Research 5 (3) (2010) 1-16.

[18] F. Mathieux, D. Brissaud, L. Roucoules, L. Lescuyer, Connecting cad and plm systems with ecodesign software : Current experiences and futures opportunities, in: International Conference on Engineering Design, 2007.

[19] L. T. Blessing, A. Chakrabarti, DRM, a Design Research Methodology, no. ISBN 978-184882-586-4, Springer-Verlag, London, 2009.

[20] D. Millet, Intégration de l'environnement en conception, l'entreprise et le développement durable, ISBN13: 978-2-7462-0732-5, Hermes Science, 2003.

[21] D. Brissaud, S. Tichkiewitch, P. Zwolinski, Innovation in Life Cycle Enginnering and Sustainable Development, Springer, 2006.

[22] R. Karlsson, C. Luttropp, Ecodesign: what's happening? an overview of the subject area of ecodesign and of the papers in this special issue, Journal of Cleaner Production 14 (2006) 1291-1298.

[23] S. Le Pochat, G. Bertoluci, D. Froelich, Integrating ecodesign by conducting changes in smes, Journal of Cleaner Production 15 (7) (2007) 671-680.

[24] D. Millet, L. Bistagnino, C. Lanzavecchia, R. Camous, T. Poldma, Does the potential of the use of lca match the design team needs?, Journal of Cleaner Production 15 (2007) 335-346.

[25] M. Braungart, W. McDonough, A. Bollinger, Cradle-to-cradle design: creating healthy emission - a strategy for eco-effective product and systems design, Journal of Cleaner Production 15 (2007) 1337-1348.

[26] B. B. Frey, J. H. Lohmeier, S. W. Lee, N. Tollefson, Measuring collaboration among grant partners, American Journal of Evaluation 27 (3) (2006) 383-392.

[27] S. C.-Y. Lu, W. Elmaraghy, G. Schuh, R. Wilhelm, A scientific foundation of collaborative engineering, Annals of the CIRP 56 (2) (2007) 605-634.

[28] G.-J. de Vreede, R. O. Briggs, Collaboration engineering: Designing repeatable processes for high-value collaborative tasks, in: Proceedings of the 38th Hawaii International Conference on System Sciences, 2005.

[29] ISO (International Organization for Standardization) Environmental Management Life Cycle Assessment Principles and Framework. ISO 14040-44: 2006, ISO, 2006.

[30] ISO (International Organization for Standardization) Produits mécaniques Méthodologie d'éco-conception (Ecodesign methodology for mechanical products). ISO XPE01005: 2009 (F), ISO, 2009.

[31] M. Rio, T. Reyes, L. Roucoules, A framework for eco-design : an interface between lca and design process, International Journal of Engineering IX (1) (2011) 121-126. 
[32] C. Luttropp, J. Lagerstedt, Ecodesign and the ten golden rules: Generic advice for merging environmental aspects into product development., Journal of Cleaner Production 14 (2006) 1396-1408.

[33] T. Bhamra, S. Evans, T. McAloone, M.Simon, A. Pode, A. Sweatman, Integrating environmental decision into the product development process in the early stages, in: Proceedings EcoDesign'99: First international symposium on environmentally conscious design and inverse manufacturing. IEEE computer society, 1999.

[34] P. Ullman, T. Dietterich, L. Stauffer, A model of mechnical design process based on empirical data, Artificial interlligence in engineering design and manufacturing 211 (1988) $35-52$.

[35] B. Eynard, T. Gallet, P. Nowak, L. Roucoules, Uml based specifications of pdm product structure and workflow, Computers in Industry 55 (2004) 301-316.

[36] M. Iraqi, M. Kleiner, L. Roucoules, Model-based (mechanical) product design, in: MoDELS 2011, 2011, pp. 548-562.

[37] ISO (International Organization for Standardization) Industrial Automation Systems Concepts and Rules for Enterprise Models. ISO 14258: 1994, ISO, 1994.

[38] M. Rio, T. Reyes, L. Roucoules, Toward proactive eco-design based on engineering and eco-desiner's software interface modeling, International conference on engineering design ICED11, 2011.

[39] J. Jeswiet, M. Hauschild, Ecodesign and future environmental impacts, Material and Design 26 (7) (2005) 629-34. 